\title{
Economical aspects concerning quality control of concrete
}

\author{
Izabela Skrzypczak ${ }^{1}$ (corresponding author), Marta Stowik ${ }^{2}$ \\ ${ }^{1}$ Faculty of Civil Engineering, Environmental Protection and Architecture, Rzeszow University of \\ Technology,e-mail: izas@prz.edu.pl,ORCID: 0000-0003-0978-3040 \\ ${ }^{2}$ Faculty of Civil Engineering and Architecture, Lublin University of Technology, Lublin, Poland, \\ e-mail:m.slowik@pollub.pl,ORCID:0000-0001-9627-3625
}

\begin{abstract}
The paper deals with economical aspects concerning the quality control of concrete. About $70 \%$ of total concrete production is connected with the structural concrete, the subject of quality control and/or conformity. When checking the conformity criteria for a compressive strength of concrete for a small number of samples, qualification errors do not affect the formation of costs associated with losses on external deficiencies. In order to avoid costs related to qualification errors and losses on external deficiencies, the number of samples should be set larger than the minimum (included in contract's clauses). Furthermore, the designer recommendations should be indicated in the specification. In the paper the costs concerning quality control for concrete have been analyzed.
\end{abstract}

Keywords: compressive strength of concrete, codes of practice

\section{Introduction}

Concrete is currently most widely used building material in the world. European concrete industry produces about 537 million $\mathrm{m} 3$ of concrete per year and about $70 \%$ of the production is structural concrete, the subject of quality control and/or conformity. The global cost of quality control is very high and it inclines that producers shift some cost and risk on customers, i.e. investors and contractors of concrete buildings. According to the politics of leading organizations and groups of concrete producers, the appropriate and frequent changes of recommendations are introduced in codes, for instance different criteria for concrete quality have been applied in the following versions of standards for concrete specification, performance, production and conformity.

It should be emphasized that conformity testing due to recommended criteria are not always the statistical control. Such situation can take place when according to the European standard EN 206 [1] the conformity control is checked for a number of samples $\mathrm{n}<15$, especially when $n=3$. The control is of the statistical character when the information obtained as result of the experimental trial leads to objective conclusions, consistent with the principles of mathematical statistics. A small sample can raise doubts about correctness of the characteristics estimation and of the proper qualification of a verified material batch. Arrangements of a statistical quality control result in a ,strategic game" between producer and customer, and the standard conformity criteria can be treated as a result of a ,specific" compromise between the requirements for quality, economy and safety $[2,3]$. The control of 
concrete production and a final inspection should be based on the assumption of producer's and consumer's risk being split between them and the verification whether delivered batches of concrete meet the conformity criteria. However, in practice, there are no statistical quality control methods that would be free of qualification errors.

\section{Quality control of concrete compressive strength}

Concrete should be subject to production control within responsibility of a producer according to EN 206 [1]. The inspection must include all steps and measures necessary to establish conformity properties of concrete with specified requirements as well as activities starting from the choice of materials, through a concrete mixture design, concrete production and testing, and finally analyzing test results. The final analysis should be performed on the basis of standard criteria $[4,5,6]$.

Production control, conformity and identity are random and mostly statistical. Statistical nature of the control is determined by random sampling method, analysis of test results and conclusions are drown up based on the statistics principles. It does not matter whether the description of tested characteristics is quantitative (quantitative statistics) or qualitative (qualitative statistics) [7]. Conformity control of concrete compressive strength is carried out on concrete with specific class or on concrete families and it gives the basis for deciding about the quality of verified concrete.

European standard EN 206, as regards to concrete compressive strength, distinguishes initial production and continuous production for which the sampling plan and conformity criteria are different. Initial production covers the production until at least 15 test results within a period not exceeding 12 months [1] (Table 1).

Table 1. Conformity criteria for compressive strength according to EN 206.

\begin{tabular}{|c|c|c|c|}
\hline & & Criterion 1 & Criterion 2 \\
\hline Production & „n” number of test & $\begin{array}{c}\text { Mean from },, n ” \\
\text { results }\left(\mathrm{f}_{\mathrm{cm}}\right) \\
{\left[\mathrm{N} / \mathrm{mm}^{2}\right]}\end{array}$ & $\begin{array}{c}\text { Any single test } \\
\text { result } \\
\left(\mathrm{f}_{\mathrm{ci}}\right) \\
{\left[\mathrm{N} / \mathrm{mm}^{2}\right]}\end{array}$ \\
\hline Initial & $<15$ & $\geq \mathrm{fck}+4$ & $\geq \mathrm{fck}-4$ \\
\hline Continuous & $\geq 15$ & $\geq \mathrm{fck}+1,48 \sigma$ & $\geq \mathrm{fck}-4$ \\
\hline
\end{tabular}

For concrete quality assessment on the grounds of conformity criteria of compressive strength an off-line quality control method is used. Control procedure is used when the production of a batch of concrete is completed. Final inspection is carried out since manufacturing stage is completed, and as the aim is not to control them or influence on the process, but to protect the recipient from accepting concrete that does not meet quality standards (i.e. relevant conformity criteria formulated in [1]).

The compound criteria for initial production and number of samples $n=3$ can have unfavorable effects to both - producer and customer. The most important defects of the criteria are following $[8,9,10,11]$ :

- Probability of concrete acceptance is not always compromise between risk of a producer and a customer. Accepted criteria may lead to excessive customer risk, especially in case of log-normal distribution of compressive strength. 
- In case of the compliance compound criteria, a higher value of acceptance probability $\mathrm{Pa}$ corresponds to larger variability of concrete strength.

- For standard conformity criteria, probability of acceptance increases with the increase of standard deviation of concrete compressive strength.

Generally, the usefulness of statistical criteria for the small number of samples, expressed by the probability that a batch of concrete with defectiveness fraction can be accepted, is questioned. The relationship between concrete quality and defectiveness fraction can be described using the Average Outgoing Quality Curve [12,13]. When the Average Outgoing Quality Level is higher than 0.05, the concrete class is not reached (Fig. 1). This condition results from the definition of a standardized concrete class.

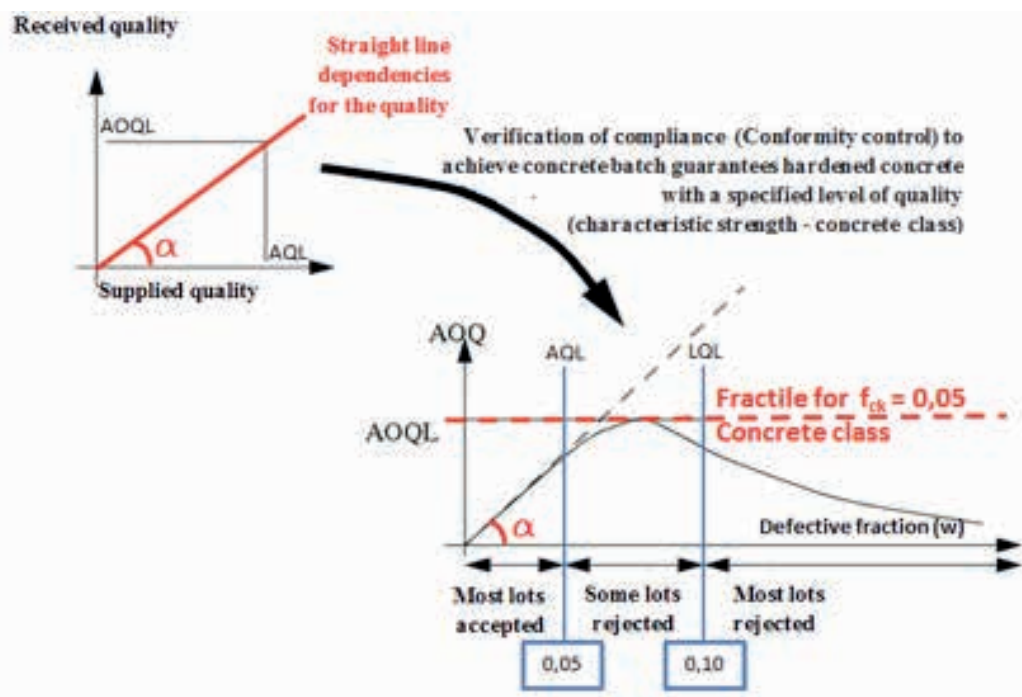

Fig. 1. Relationship between the quality of delivered lots to conformity control and the concrete class (outgoing quality).

Discriminatory power of statistic conformity criteria should be large enough to show evident diversity between the costs for the qualification with errors and the costs for the flawless qualification $[14,15]$. It should be emphasized that in practice there is no statistic quality control methods that would be free of errors - errors of the first type (concrete batch of satisfactory quality will be rejected) and the second kind (concrete batch of lower quality will be accepted). It is easy to make a mistake in checking conformity criteria in case of number of a samples $n=3$. Conformity criteria do not meet the requirements in terms of quality, hence the attempt to analyze these criteria in respect to economic requirements.

\section{Quality control costs}

Quality costs include all the costs related to conducting inspections in the company. They include costs associated with the performance or omission of control activities, costs of reparation and replacement of defective parts, costs resulting from customer loss and costs of decreasing company's position on the market. The classification of quality control costs covers: costs of prevention, costs of testing and evaluation, losses on internal deficiencies, losses on external deficiencies [16]. 
The cost of final inspection is a total of testing and evaluation costs and losses on internal and external deficiencies. Costs of testing depend on the cost of the control sample $k_{p r}$ and the number of controlled samples n; expected control costs when using a singlestage plan are as follows:

$$
K_{p r}(w)=P_{a}(w) \cdot n \cdot k_{p r}+\left(1-P_{a}(w)\right) \cdot N \cdot k_{p r}
$$

where: $\mathrm{P}_{\mathrm{a}}(w)$ - probability of acceptance of a concrete batch with a given defectiveness w

$n$ - number of sample,

$N-$ lot number defined as:

$$
N=\frac{V_{\text {prod }}}{V_{\text {sample }}}
$$

where: $V_{\text {prod }}$ - volume of the concrete batch,

$V_{\text {sample }}$ - volume of a test sample (cubic sample $V_{\text {sample }}=3.37510^{-3} \mathrm{~m}^{3}$ ).

Total expected cost of internal defectiveness $K_{b w}$ in a testing plan according to the assessment is as follows:

$$
K_{b w}(w)=P_{a}(w) \cdot n \cdot k_{b w}+\left(1-P_{a}(w)\right) \cdot N_{1} \cdot k_{b w}
$$

where: $k_{b w}$ - cost in case of non-compliant compressive strength of concrete not applied in structural member.

Losses on external deficiencies can be determined using the equation:

$$
K_{b z}(w)=P_{a}(A O Q L) \cdot n \cdot k_{b z}+\left(1-P_{a}(A O Q)\right) \cdot N \cdot k_{b z}
$$

where: $k_{b z}$ - cost of repairing a structural member in case of non-compliant compressive strength of concrete, tests.

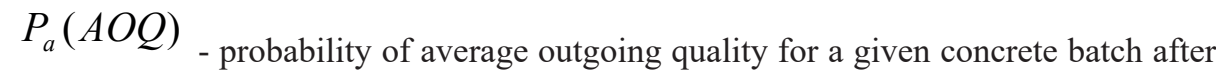
Average outgoing quality is expressed as:

$$
A O Q=P_{a}(w) \cdot w
$$

$A O Q$ - average outgoing quality of a concrete batch after conformity control.

In the performed analysis of quality control costs, the OC (Operating Characteristic) curve and the AOQ (Average Outgoing Quality) curve have been used.

\section{Final inspection costs and qualification errors}

In practice, there are no statistical quality control methods that are free from qualification errors. The probability of recognizing a sample as defective is therefore expressed by the formula

$$
w^{*}=w(1-\beta)+(1-w) \alpha
$$


where: $w$-defectiveness of a sample during inspection of a produced concrete,

$\beta$ - probability of qualification error of recognizing a defective sample as a flawless one, recipient's risk,

$\boldsymbol{\alpha}$ - probability of qualification error of recognizing a flawless sample as a defective one, producer's risk,

In case of qualification errors, the expected costs of research take the following form:

$$
\begin{aligned}
& K_{p r}^{*}(w)=P_{a}^{*}\left(w^{*}\right) \cdot n \cdot k_{p r}+\left(1-P_{a} *\left(w^{*}\right)\right) \cdot N \cdot k_{p r} \\
& K_{b w}^{*}(w)=P_{a} *\left(w^{*}\right) \cdot n \cdot k_{b w}+\left(1-P_{a} *\left(w^{*}\right)\right) \cdot N_{l} \cdot k_{b w} \\
& K_{b z}^{*}(w)=P_{a} *\left(A O Q^{*}\right) \cdot n \cdot k_{b z}+\left(1-P_{a} *\left(A O Q^{*}\right)\right) \cdot N \cdot k_{b z}
\end{aligned}
$$

where: $P_{a}^{*}(\ldots)$ - probability of accepting a material batch with presence of qualification errors.

In concrete production the good quality of concrete corresponds to the concrete class (the characteristic strength $f_{c k}$ - the 0.05 fractile of the theoretical distribution of concrete strength). In practice, the fractile can be smaller or higher than 0.05 . The defectiveness of a sample $\mathrm{w}$ in the case when the concrete strength is below fck is defined as:

$$
P\left(f_{c} \leq f_{c k}\right)=w
$$

where: $f_{c}$ is the compressive strength, which is a random variable.

The operation characteristic curve of the conformity criterion (OC-curve or OC-line) is the function of $P_{a}(w)$, where $P_{a}$ is the probability of acceptance, (Fig. 2). The rejection probability of a good quality batch $\alpha=1-P a$, and the acceptance probability of a bad quality batch $\beta$, should be balanced between producers and clients. However, the equality of rejection probability and acceptance probability does not mean that producer's and the client's risk are the same.

a)

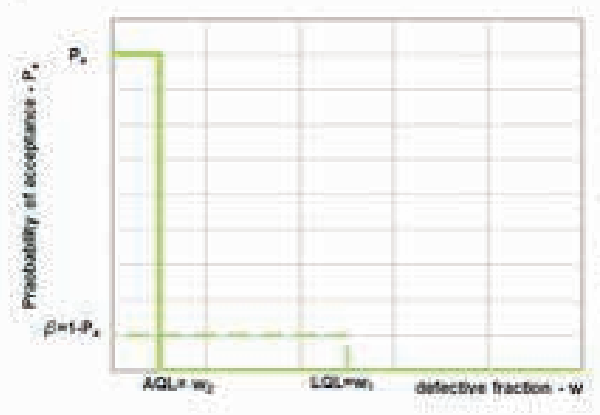

b)

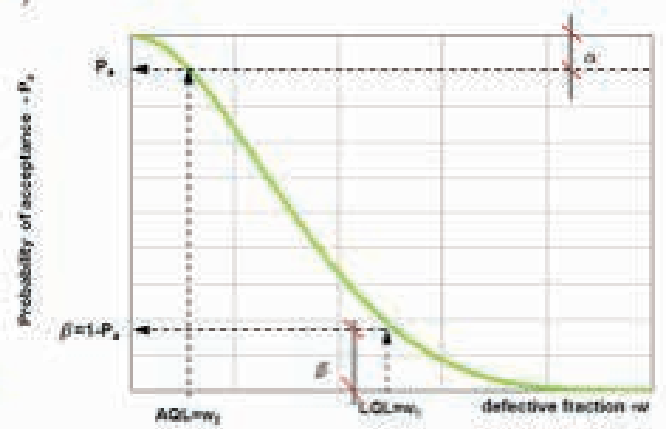

Fig. 2. Diagram of: a) an ideal OC-line and b) a real OC-line

\section{Costs analysis of final inspection}

Analysis of the conformity criteria based on economic indicators requires the determination of the total cost of final inspection. The analysis was performed for the reinforced concrete deck plate of a three-span bridge structure of the theoretical span $L_{T}=28.8$ 
$+38.4+28.8 \mathrm{~m}$. The dimensions of plate were: thickness $0.25 \mathrm{~m}$, total width $14 \mathrm{~m}$. The plate was made with the concrete class $\mathrm{C} 30 / 37$ for which the real defectiveness of concrete was 0.07. The costs of tests and evaluation were calculated at the assumed recipient and producer risk level. The costs were estimated for a flawless control as well as with qualification errors. It was assumed that the errors $\alpha$ and $\beta$ are equal 0.05 (Fig. 3). Calculations were performed according to the described procedure.

a)

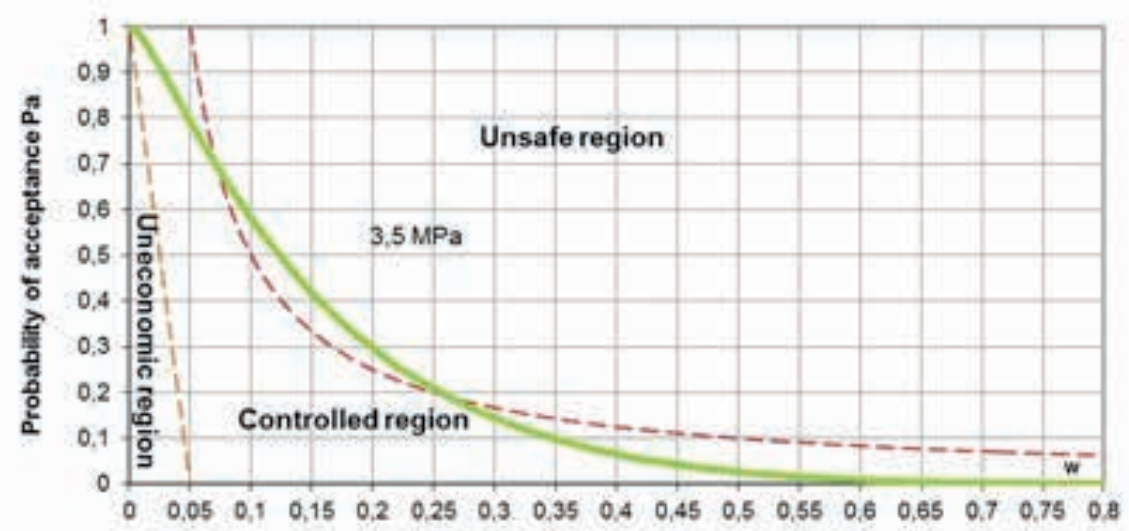

b)

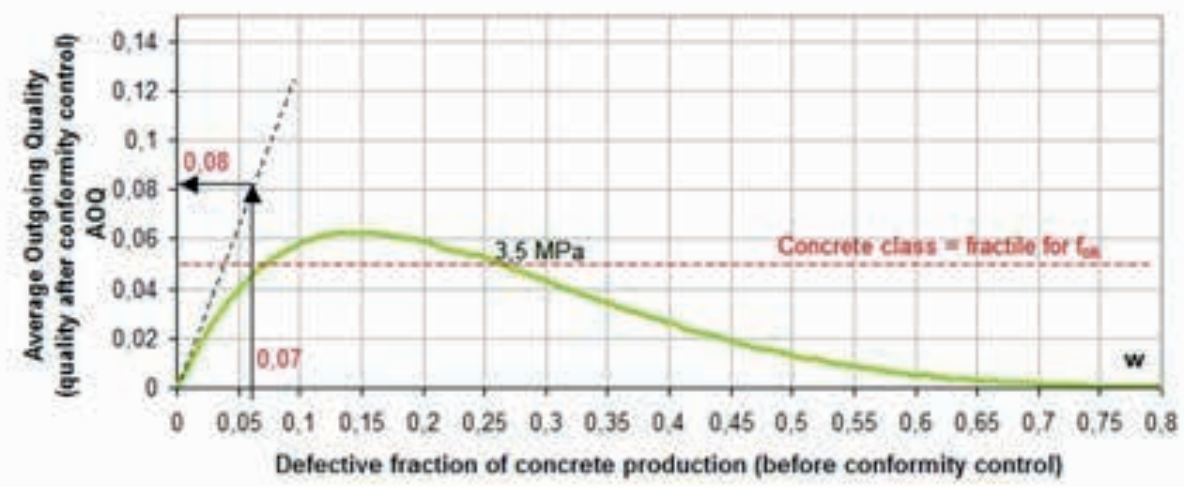

Fig. 3. Diagram of: a) the $\mathrm{OC}$ line, b) the $\mathrm{AOQ}$ line for conformity criteria for $\mathrm{n}=3$

and for standard deviation $3.5 \mathrm{MPa}$

In order to determine costs associated with the verification of the quality of concrete for a small number of samples it was assumed that the cost of testing samples was 100 EURO, the cost of internal deficiency is 1,000 EURO (losses incurred in case of a batch of material understood as a mixer with a volume of $6 \mathrm{~m} 3$ ), the cost of external deficiency 50,000 EURO. The obtained results are presented in Table 2. 
Economical aspects concerning quality control of concrete

\begin{tabular}{|l|c|c|c|}
\hline \multicolumn{1}{|c|}{$\begin{array}{c}\text { Qualification type } \\
\text { Control type }\end{array}$} & $\begin{array}{c}\text { Flawless qualifica- } \\
\text { tion } \\
{[\text { euros }]}\end{array}$ & $\begin{array}{c}\text { Bualification with } \\
\text { errors } \\
{[\text { euros }]}\end{array}$ & B/A \\
\hline $\begin{array}{l}\text { Testing and evalu- } \\
\text { ation }\end{array}$ & 358 & 397 & 1.11 \\
\hline $\begin{array}{l}\text { Losses on internal } \\
\text { deficiencies }\end{array}$ & 1008 & 1483 & 1.47 \\
\hline $\begin{array}{l}\text { Losses on external } \\
\text { deficiencies }\end{array}$ & 48029 & 48278 & 1.01 \\
\hline Total cost & 49395 & 50158 & 1.02 \\
\hline
\end{tabular}

Costs of final inspection in case of flawless qualification and control with qualification were obtained on the same level. It showed that when performing testing concrete conformity control on the basis of small sample (the number of specimens $n=3$ ) the test is not reliable. Therefore, the usage of small sample to quality control can lead to refrain accurate final inspection and reliable quality control and, consequently it might be the reason why the quality of a produced concrete is being reduced.

Qualification errors appearing during control do not have a major impact on a formation of costs related to losses on external deficiencies. This means that a sample of a small number is less selective in terms of quality verification, as well as the economy.

\section{Conclusions}

The control costs in both cases are similar, and thus control for $n=3$ is objectively meaningless, although it has psychological effects. The costs associated with quality control as recommended by the European standard EN 206 [1] of dual conformity criteria for a sample of a small number with flawless qualification and qualification errors are comparable, what indicates that the recommended in the norm quality control procedures are not consistent with the requirements of the economy.

In order to avoid costs related to qualification errors and losses on external deficiencies the number should be set larger than the minimum.

In case of conformity assessment of concrete properties, the risk is borne not only by the producer and the recipient of concrete but also the investor, the user of the building and, in case of a construction disaster, the whole society. Disparities of the effects of making wrong decision are obvious and considerable. Recommendations in the current standards include only the producer's risk whereas the risk of the customer remains vague. The principle of equality of market participants suggests that the criteria for conformity assessment should take into account rational and conscious risk-sharing. The EU Directive on the standardization enables treating requirements contained in the norm as a minimum. The recipient of concrete may agree with the supplier conditions that allow a conscious choice of a risk level.

One of possible strategies is to balance the risk of a producer and a recipient. The reconciliation of an acceptable risk of a producer and a recipient of concrete, for instance, presumption of equal risk on both sides, allows to estimate probability of conformity certification and selection of a suitable control plan. 


\section{References:}

[1] EN 206-1:2013, Concrete - Part 1: Specification, performance, production and conformity.

[2] Holicky, M., Vorlicek. M., Fractile estimation and sampling inspection in building, Acta Polytechnica, CVUT Praha, 1992.Vol. 32. Issue 1, 87-96.

[3] Sual I. Gass, and Arjang A. Assad, An annotated timeline of operation research. An informal history. Springer Science and Business Media, 2005.

[4] Harrison. T.A., Crompton, S., Eastwood. C., Richardson. G., Sym, R., Guidance on the application of the EN 206-1 conformity rules, Quarry Products Association, 2001.

[5] Czarnecki, L. et al., Concrete according to PN EN 206-1- The comment - Collective work, Polish Cement and PKN, Cracow, Poland, 2004.

[6] Lynch, B., Kelly, J., McGrath, M., Murphy, B., Newell, J., The new Concrete Standards, An Introduction to EN 206-1, The Irish Concrete Society, 2004.

[7] Montgomery, D.C., Introduction to Statistical Quality Control, 5th Ed., Wiley, 2005.

[8] Taerwe, L., Evaluation of compound compliance criteria for concrete strength, Materials and Structures, 1998, 21, pp. 13-20.

[9] Catarino, J.M.R., Statistical criteria for acceptance of materials performance of concrete standards ENV 206;1993 and prEN206:1997. Proceedings of 12th ERMCO Congress, Vol. 1, Lisbon, 1998.

[10] Brunarski, L., The mathematical basis for shaping the strength of materials conformity criteria, Scientific Work of the Institute of Building Technology, Publishing of the Institute of Building Technology, Warsaw 2009 (in Polish).

[11] Szczygielska, E., Tur, V., The study of the conformity criterion for compressive strength of concrete based on order statistics, Civil Engineering and Architecture, 2013, Vol. 12, Issue 3, 223-230.

[12] Taerwe, L., Caspeele, R., Conformity control of concrete: some basic aspects, Proceedings of 4-th International Probabilistic Symposium, Ghent, Belgium, 2006, 57-70.

[13] Skrzypczak, I., Analysis of criteria of quality assessment for concrete and their influence on risk of the producer and the recipient, The Publisher of the Rzeszow University of Technology, Rzeszow, Poland, 2013 (in Polish).

[14] Evans, J., Lindsay, W., The Management and Control of Quality, West Publishing Company, 1989.

[15] Banovac, E., Pavlovic, D., Vistica N., Mathematical aspects of acceptance sampling procedure. International Journal of Mathematical Models and Methods in Applied Sciences, 2012, Issue 5, Vol. 6, 625-633.

[16] Dumicic, K., Bahovec, V., Kurnoga Zivadinovic, N., Studying an OC Curve of an Acceptance Sampling Plan: A Statistical Quality Control Tool, Proceedings of the 7th WSEAS International Conference on Mathematics \& Computers in Business \& Economics, Cavtat, Croatia, 2006, 1-6. 